\title{
Registration and spectral analysis of waveforms of 10.24.2019 earthquake in the Caucasus using the new IGES-006 seismic sensor
}

\author{
J. K. Karapetyan ${ }^{1}$, A. S. Gasparyan ${ }^{1}$, S. R. Shakhparonyan ${ }^{1}$, and R. K. Karapetyan ${ }^{1}$
}

Received 19 April 2020; accepted 10 September 2020; published 18 October 2020.

The paper considers the application possibility of the new IGES-006 seismic sensor for monitoring tasks. The sensor is developed at the Institute of Geophysics and Engineering Seismology after A. Nazarov of the National Academy of Sciences of Armenia. The IGES-006 sensor can be used both as part of various seismic monitoring systems and for solving special engineering problems. The sensor prototype has successfully passed laboratory and field tests, including the seismic monitoring mode. To assess the possibility of using the IGES-006 sensor as an import-substituting scientific device, it was compared with the Russian SPV-3K sensor, which is quite similar in parameters. A comparative analysis of seismic signals recorded using IGES-006 and SPV-3K sensors in the time and frequency domains have been carried out. The comparison results indicate the prospects for mass production of IGES-006. KEYWORDS: earthquake; seismic signal; portable seismic sensor; seismic sensor; spectral analysis.

Citation: Karapetyan, J. K., A. S. Gasparyan, S. R. Shakhparonyan, and R. K. Karapetyan (2020), Registration and spectral analysis of waveforms of 10.24.2019 earthquake in the Caucasus using the new IGES-006 seismic sensor, Russ. J. Earth. Sci., 20, ES6002, doi:10.2205/2020ES000742.

\section{Introduction}

Instrumental observations are an integral part of geophysical research [Dzeboev et al., 2019. IsmailZadeh et al., 2020, Karapetyan et al., 2020. To upgrade the monitoring systems and to solve fundamental problems of seismology, engineering seismology, and earthquake engineering, it is necessary to constantly improve the quality of instrumental observations. This requires the development and implementation of new generation instruments. First of all, this concerns the development of seismic sensors, their dynamic, and frequency ranges.

For many years, the team of the Institute of Geophysics and Engineering Seismology after A. Nazarov of the National Academy of Sciences of Ar-

\footnotetext{
${ }^{1}$ Institute of Geophysics and Engineering Seismology after A. Nazarov NAS RA, Gyumri, Armenia

Copyright 2020 by the Geophysical Center RAS. http://rjes.wdcb.ru/doi/2020ES000742-res.html
}

menia (IGES NAS RA) has been actively working on the development of modern geophysical instruments for solving scientific and special engineering problems. One of the traditional directions for the Institute is the development of seismometric equipment, including those based on the SM-3 seismic sensors. The main results of these developments over the past 30 years are reflected in publications [Sarkgsyan, 2014, 2010, Karapetyan and Gasparyan, 2018.

Currently, the problem of improving the quality of mass seismological observations is solved by equipping observational seismometric and engineering-seismometric stations with devices of a new generation. This makes it possible to perform high-level monitoring (registration and analysis of earthquakes, micro-earthquakes, etc.) of urbanized areas, especially critical facilities, buildings, and structures.

It has to be noted that the models of seismological instruments, developed and manufactured before the 1990s, can no longer satisfy the increased 
requirements. In recent years, the elemental base of electronic components has been updated, new opportunities for information technologies and improved designs have appeared, including the mechanical elements of the suspension for vertical and horizontal seismometers [Rykov, 1992, 2002. Sidorin, 2018, Vasilev et al., 2016, Karapetyan, 2018a, 2018b; Karapetyan and Karapetyan, 2019.

All this gives rise to works in IGES NAS RA on the modernization of existing seismometers and the creation of domestic, much cheaper unique seismic devices with relatively simple designs and capable of replacing expensive foreign analogs.

\section{Short Period Seismic Sensor}

In 1975 V. A. Tokmakov developed the SM-3 seismic receiver, which is still widely used in both seismological and engineering research. The seismic receiver SM-3 is designed to convert mechanical vibrations into vibrations of electric current. It can be used to measure vertical and horizontal vibrations in various systems. SM-3 has a smooth natural frequency adjustment up to $0.5 \mathrm{~Hz}$ and a temperature compensator for the vertical version of the seismometer. It can be easily readjusted from vertical to horizontal and vice versa [Tokmakov, 1975. There is evidence from some US sources about the use of the SM-3 seismic receiver as a standard for calibrating seismic instruments [Mackey et al., 2013.

The main disadvantages of the SM-3 seismic receiver are: heavy weight, large overall dimensions, difficulties in adjustment during operation, instability of the zero position, the low attenuation coefficient of natural vibrations of the pendulum.

The authors of this work summarized the experience of the best domestic developments, analyzed the achievements and problems of modern seismometry, and proposed the most economically and quickly feasible way of creating a new seismic receiver - the modernization of the SM-3. The purpose of the modernization is to reduce weight, increase the attenuation coefficient, simplify the design, improve performance, and ensure the stability of the zero position of the device.

The weight of the SM-3 is $7.7 \mathrm{~kg}$. It contains more than 30 high-precision parts, that require the manufacture by a highly skilled workforce and spe-

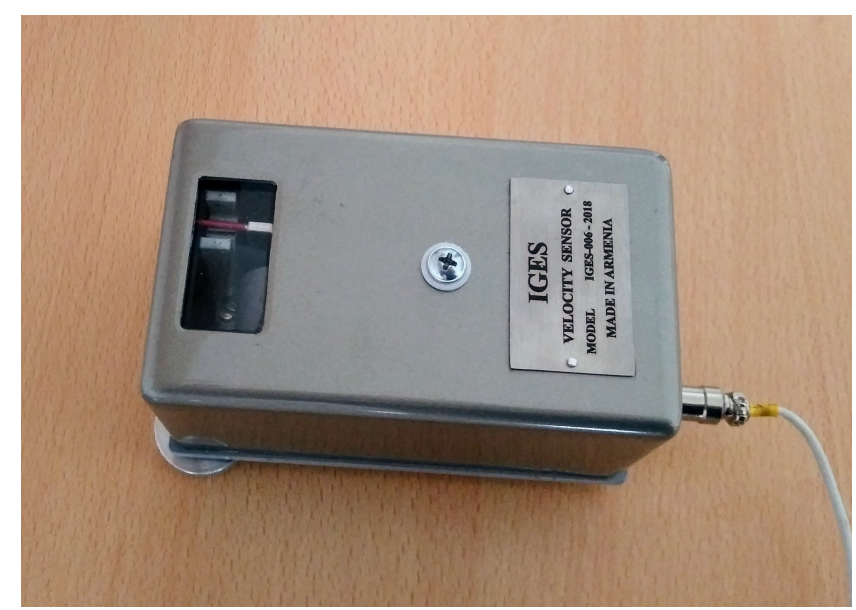

Figure 1. The general view of the seismic sensor IGES-006.

cial tooling. In turn, the upgraded version of the device, which was named IGES-006, weighs less than $1 \mathrm{~kg}$, contains less than 10 parts, which do not require any special high-precision production.

When operating in the field conditions the following inconveniences arise with SM-3: to set up the device, one must open the cover, uncage, set the zero position of the pendulum and close the cover again. After closing the cover, in a while the temperature inside the device changes, which leads to a change in the zero position of the pendulum. In this regard, there is a need for repeated re-adjustment. When used in a network of multiple sensors, the setup process becomes laborious, tedious, and time-consuming. The upgraded IGES006 sensor has improved performance. The release and the setting of the pendulum to the zero position are carried out without opening the cover of the device.

The developed seismometer is designed to upgrade existing national networks of seismological and engineering-seismometric observations, both in Armenia and abroad[Karapetyan, 2017, 2018c, Karapetyan et al., 2020. The general view of the seismic sensor IGES-006 is shown in Figure 1.

Figure 2 shows the structural diagram of the IGES-006 seismic receiver. The sensor is located in a housing in which an oscillating pendulum with inertial mass and a coil on the same axis with the inertial mass are installed. The sensor also has a neodymium magnet located on the housing coaxially with the coil and a copper core. Structurally, the seismic receiver is an inertial pendulum with its 


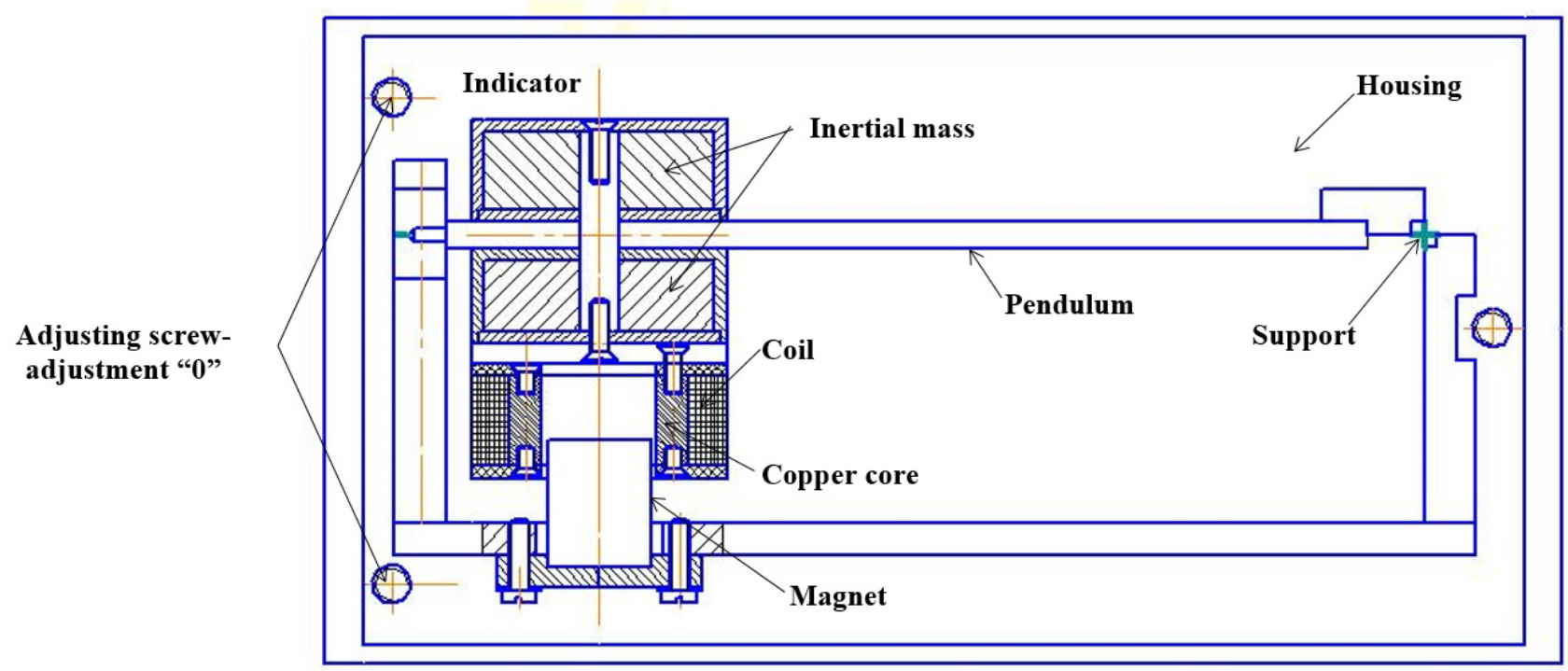

Figure 2. Structural diagram of the seismic sensor IGES-006.

own period adjustable up to 3 sec Figure 2 .

The seismic receiver is housed in a waterproof stainless-steel case with an output connector for connection to the logger. Three versions of the seismic receiver have been developed: with periods of natural oscillations of the pendulum 1.0, 1.5, and $2.5 \mathrm{sec}$. The attenuation coefficient of the pendulums is critical. The pendulum is set to zero position without opening the cover of the device. The inertial masses and the coil are balanced relative to the swing axis of the pendulum, which makes it possible to abandon the use of spiral springs. This, in turn, eliminates the temperature instability of the seismic sensor.

With a change in temperature for SM-3 seismometer, the pendulum changes its position of equilibrium, since when the temperature changes, the spring stiffness mainly changes due to a change in its elastic properties [Savarensky and Kirnos, 1995 .

To determine the thermal stability of the SM-3 seismic receiver and the upgraded IGES-006 sensor, joint laboratory temperature tests were carried out. At a temperature of $+50^{\circ} \mathrm{C}$, the displacement of the SM-3 pendulum was $10 \mathrm{~mm}$, while for IGES-006 the displacement of the pendulum was not observed. There is no need to use springs to set the pendulum to zero position.

The vertical sensor has an electromechanical drive to maintain the zero position of the pendulum. The drive is powered by a built-in Li-Ion battery, which ensures continuous operation of the device for at least one year.

The implemented technologies provide a cheaper alternative for the development of mass seismic observation facilities in Armenia in comparison with the existing foreign programs for the modernization of seismic monitoring networks. The main characteristics of the IGES-006 seismometer are shown in Table 1.

\section{Measurement Results in Seismic Monitoring Mode}

IGES-006 successfully passed laboratory and field tests and was recommended for test use in monitoring mode, in particular, at stations of regional seismic networks in areas with high seismic hazard.

For testing in monitoring mode from September 30 to October 2, 2019, in the Republic of North Ossetia-Alania (Russian Federation), the IGES-006 sensor was installed at two seismic stations with digital control units: in Vladikavkaz and in the village of Karmadon Figure 3. The stations are part of the seismic network of the Geophysical Institute VSC RAS.

After the installation of the IGES-006 seismic receivers in the Western Caucasus region on October 24, 2019, an earthquake occurred with the following focal parameters: 2019-10-24 15:41:41, latitude 
Table 1. The main characteristics of the IGES-006 seismometer

\begin{tabular}{rlcc}
\hline No. & Specifications & Dimension & Value \\
\hline & Working frequency range & $\mathrm{Hz}$ & $0.3-50$ \\
2 & $\begin{array}{l}\text { Irregularity of the amplitude-frequency response } \\
\text { in the operating frequency range }\end{array}$ & $\mathrm{dB}$ & 3 \\
3 & Nominal conversion factor & $\mathrm{in} \mathrm{s} / \mathrm{m}$ & 30 \\
4 & Attenuation & - & 1 \\
5 & Seismic receiver dimensions (one component) & $\mathrm{mm}$ & $70 \times 70 \times 60$ \\
6 & Weight of one seismic receiver, no more than & $\mathrm{kg}$ & 1 \\
7 & Control unit dimensions & $\mathrm{mm}$ & $205 \times 150 \times 70$ \\
8 & Control unit weight & $\mathrm{kg}$ & 1.1 \\
9 & Working temperature range & ${ }^{\circ} \mathrm{C}$ & $-60 \ldots+40$ \\
10 & Relative humidity at an ambient temperature of $25^{\circ} \mathrm{C}$ & - & 80 \\
\hline
\end{tabular}

43.12, longitude 44.57, depth $15 \mathrm{~km}, \mathrm{mb}: 3.4 / 4$. The earthquake was recorded by the SPV-3K and IGES-006 seismic receivers installed at the "Vladikavkaz" and "Karmadon" stations Figure 4.

Figure 5 and Figure 6 show the records of the horizontal component $X$ and the corresponding spectra of the waveforms of the earthquake of October 24, 2019, recorded by the IGES-006 (green) and SPV-3K (black) seismic receivers.

Comparative analysis shows that there is a good correspondence of waveforms and spectra of records obtained using IGES-006 and SPV-3K sensors. However, the first arrival of the waveforms is identified more clearly on the IGES-006 record (Figure 5 and Figure 6). The SPV-3K record shows increased (by about a factor of 2) background amplitude, which can be interpreted as instrumental noise (Figure 6).
Spectral analysis of records from the IGES-006 and SPV-3K sensors shows that, in the general case, the values of the prevailing periods coincide: $T=0.37 \mathrm{sec}$ and $T=0.55 \mathrm{sec}$ Figure 5 - records of the earthquake by the station "Karmadon" and the corresponding spectra of waveforms). The values of the prevailing periods on the spectra of the IGES006 and SPV-3K sensors coincide $T=0.20 \mathrm{sec}$ and $T=0.57 \mathrm{sec}$ Figure 6 - records of the earthquake obtained by the station "Vladikavkaz" and the corresponding spectra of waveforms). However, there are some differences when comparing spectral densities (Figure 5 and Figure 6).

To demonstrate the correspondence of the earthquake records in Figure 7 and Figure 8 are presented comparisons of waveforms and corresponding spectra for the IGES-006 and SPV-3K seis-

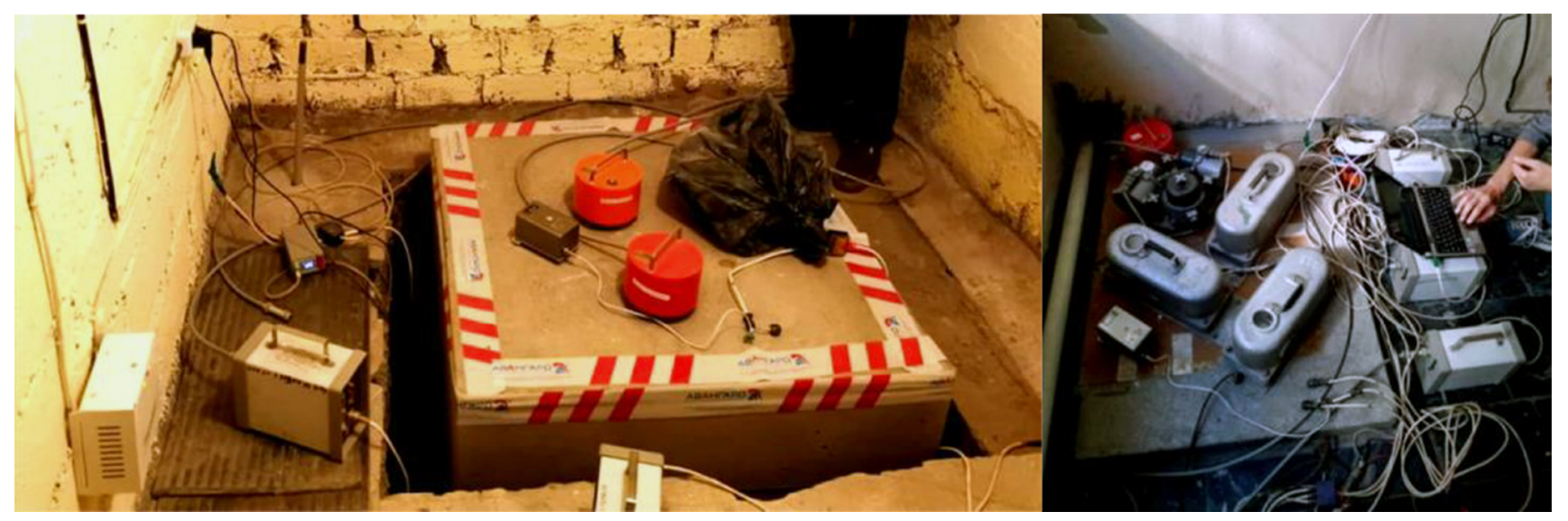

Figure 3. Seismic stations "Karmadon" (on the left) and "Vladikavkaz" (on the right), where sensors IGES-006 and SPV-3K were installed. 
Table 2. Parameters of ground vibration and seismic impact

\begin{tabular}{ccccc}
\hline & \multicolumn{2}{c}{ "Karmadon" } & \multicolumn{2}{c}{ "Vladikavkaz" } \\
\hline & IGES-006 & SPV-3K & IGES-006 & SPV-3K \\
$\mathbf{T}^{1}$ & $\mathbf{0 . 5 5 5 4}$ & $\mathbf{0 . 5 5 5 4}$ & $\mathbf{0 . 5 6 9 9}$ & $\mathbf{0 . 5 7 4 9}$ \\
$\boldsymbol{\omega}_{1}$ & 1.8005 & 1.8005 & 1.7548 & 1.7395 \\
$\mathrm{~T}^{2}$ & $\mathbf{0 . 3 7 4 5}$ & $\mathbf{0 . 3 7 4 5}$ & $\mathbf{0 . 1 9 9 8}$ & $\mathbf{0 . 2 0 0 4}$ \\
$\boldsymbol{\omega}_{2}$ & 2.6703 & 2.6703 & 5.0049 & 4.9896 \\
$\mathrm{PGV}$ & $\mathbf{6 6 . 9 3 3 7}$ & $\mathbf{4 2 . 1 9 5 3}$ & $\mathbf{2 0 1 . 9 5 2 8}$ & $\mathbf{1 2 6 . 5 6 1 3}$ \\
$\mathrm{ASI}$ & $\mathbf{5 9 . 4 3 1 0}$ & $\mathbf{4 5 . 5 5 1 9}$ & $\mathbf{1 7 1 . 7 7 0 7}$ & $\mathbf{1 1 7 . 4 4 5 6}$ \\
$\mathrm{CAV}$ & $\mathbf{3 6 5 1 5 9 . 0 0 8 6}$ & $\mathbf{2 7 8 9 7 4 . 9 0 5 1}$ & $\mathbf{7 0 6 4 9 0 . 0 5 7 1}$ & $\mathbf{5 3 1 4 6 6 . 8 2 2 9}$ \\
\hline
\end{tabular}

mometers at the "Karmadon" and "Vladikavkaz" stations.

there are some differences in the amplitude values,

Comparative analysis shows a good agreement of sitivity of the IGES-006 and SPV-3K seismic rewaveforms in both time and amplitude. However, ceivers (Figure 7 and Figure 8).

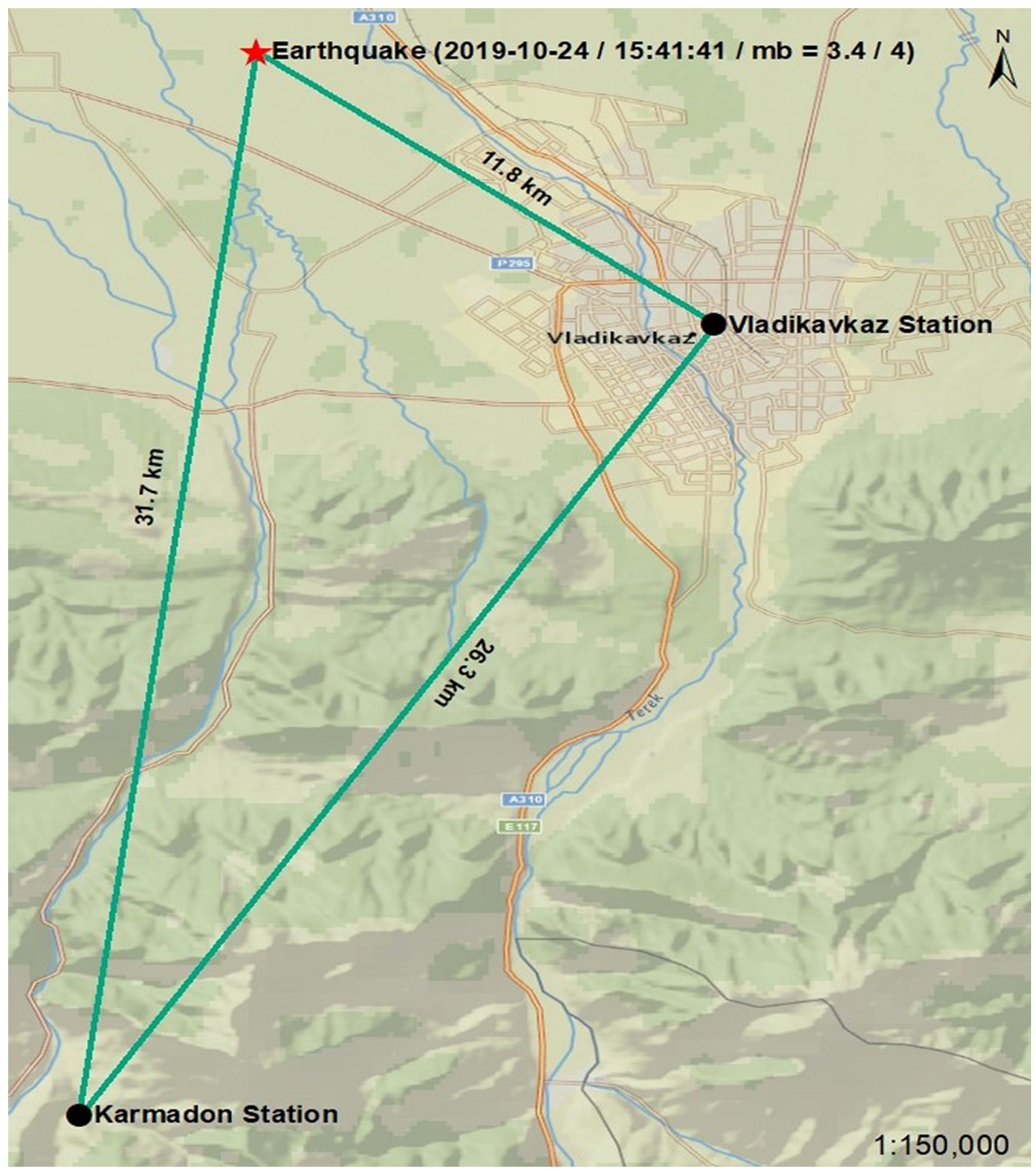

Figure 4. Location of seismic stations "Karmadon" and "Vladikavkaz" in relation to the epicenter of the earthquake of October 24, 2019. 

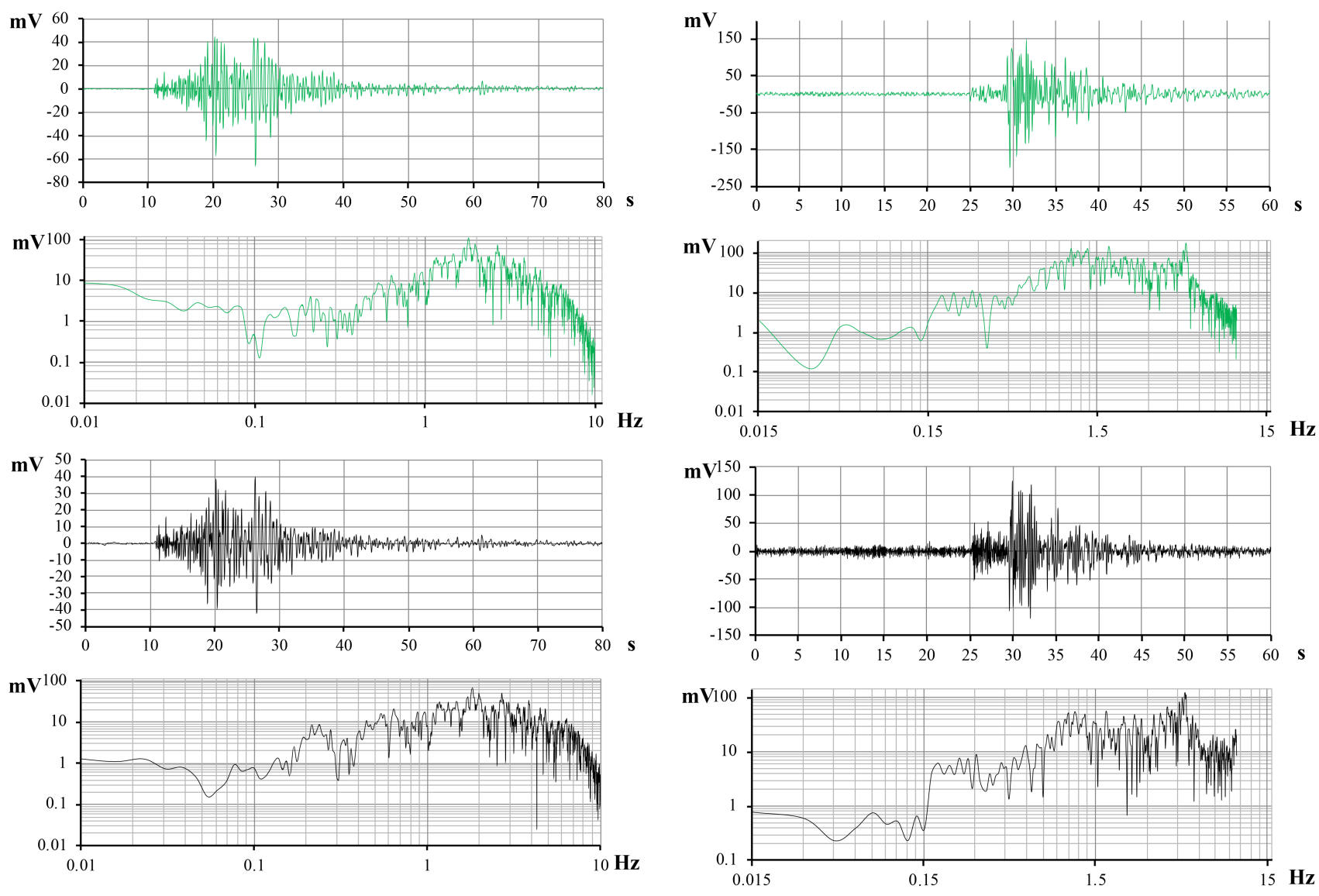

Figure 5. Records of the $X$ horizontal component of the earthquake of October 24, 2019, of the "Karmadon" station and the corresponding waveform spectra: green - IGES-006, black - SPV-3K.

Table 2 shows the quantitative parameters (Peak Ground Velocity-PGV) of ground vibrations (records from the IGES-006 and SPV-3K seismometers), and also some integral (Velocity Spectrum Intensity-VSI, Cumulative Absolute Velocity-CAV) parameters are calculated as more stable energy parameters of seismic impact [Karapetyan, 2013. Grigoryan and Karapetyan, 2008.

Comparative assessment of parameters in Table 2 shows that the maximum amplitudes on the IGES006 records are 1.59 times greater than those on the SPV-3K instrument records ("Karmadon" and "Vladikavkaz" stations). This is apparently due to the different sensitivities of the devices.

At a distance of $31.7 \mathrm{~km}$ from the epicenter Figure 4, the maximum amplitude on the IGES-006 record of the "Karmadon" station is $66.9 \mathrm{mV}$, and on the IGES-006 record of the "Vladikavkaz" sta-

tion is $201.9 \mathrm{mV}$, that is 3 times less. The ratio of the epicentral distances for the "Vladikavkaz" and "Karmadon" stations is 2.7. The ratio of the values of the integral parameters, in particular CAV, is 1.9. The same values were obtained by comparing the corresponding parameters on the SPV-3K record of the "Karmadon" and "Vladikavkaz" stations. The ratio of the values of the integral parameters, in particular ASI, which describes the spectral composition, calculated from the SPV-3K and IGES-006 records, are 2.6 and 2.9, respectively. In other words, when the distance changes 2.7 times, the maximum amplitude changes 3 times, and the CAV parameter changes 1.9 times. This is more reasonable since CAV takes into account not only the waveform, but also the recording duration and, in fact, represents an energy parameter and behaves more stable. 

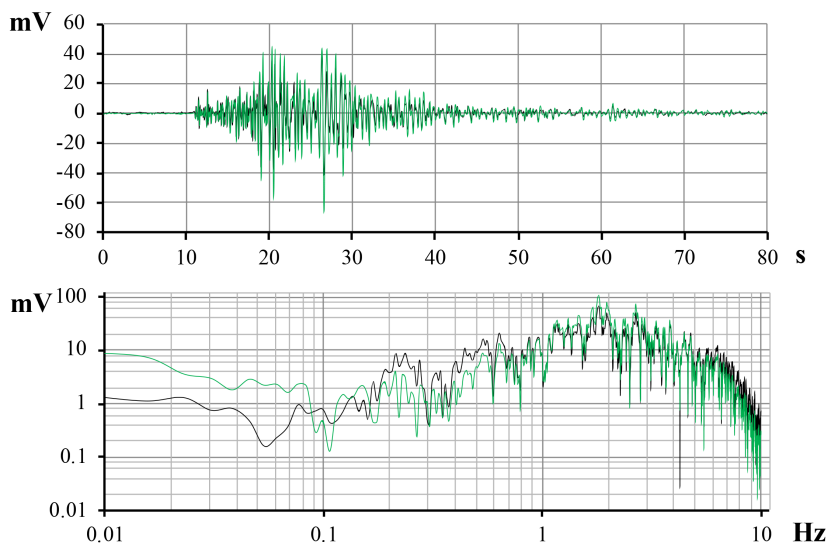

Figure 7. Comparison of waveforms and spectra of records for the IGES-006 and SPV-3K seismometers at the "Karmadon" station.

Table 2 shows that in all cases the spectra show a dominant period of $0.56 \mathrm{sec}$. Apparently, this is the main characteristic period of this earthquake.

\section{Conclusion}

A small-sized sensor for monitoring systems has been developed that meets the highest modern requirements. This is a short-period seismic sensor with periods of natural oscillations of the pendulum of $1.0,1.5$, and $2.5 \mathrm{sec}$. Its frequency response corresponds to a velocimeter and has the flattest section in the $0.3-50 \mathrm{~Hz}$ band. The model of the seismic sensor has successfully passed laboratory and field tests, including in the seismic monitoring mode.

Conducted joint tests of portable seismic sensors IGES-006 and SPV-3K indicate a good agreement for characteristics of the seismic process, recorded independently by both devices.

The studies conducted make it possible to confirm that small-sized short-period geophones can replace large and more expensive sensors.

The small-sized short-period seismometer IGES006 developed by the authors is designed to upgrade existing national seismological and engineering seismometric observations, regional and local geodynamic studies.

Acknowledgments. This work was supported by the Science Committee of the Republic of Armenia,
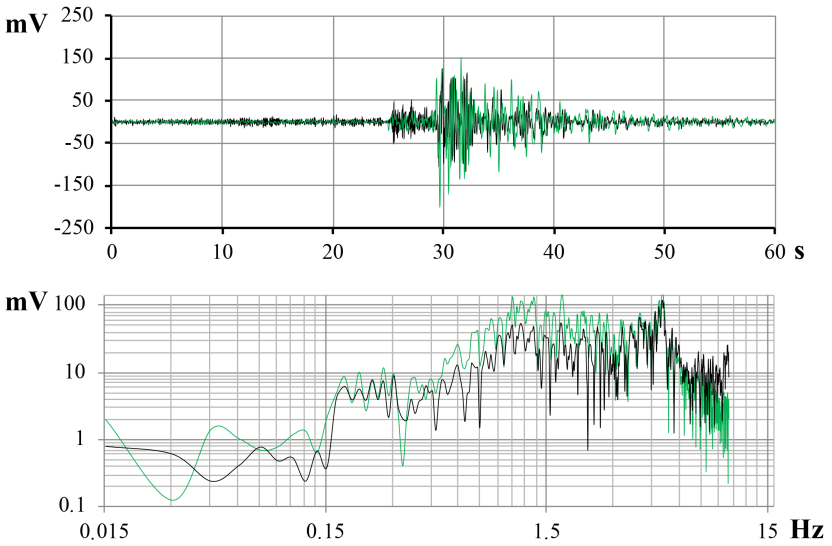

Figure 8. Comparison of waveforms and spectra of records for the IGES-006 and SPV-3K seismometers at the "Vladikavkaz" station.

in the frames of the research projects No.18SH-1E012, 15Ap_1e(2a,2b)007 and Ach-01/20.

The authors are grateful to the head of the Geophysical Institute of the Federal Scientific Center "Vladikavkaz Scientific Center of the Russian Academy of Sciences" (GPI VSC RAS) for the opportunity to place the devices at the "Vladikavkaz" and "Karmadon" stations.

\section{References}

Dzeboev, B. A., A. A. Soloviev, B. V. Dzeranov, et al. (2019), Strong earthquake-prone areas recognition based on the algorithm with a single pure training class. II. Caucasus, $M \geq 6.0$. Variable EPA method, Russ. J. Earth. Sci., 19, ES6005, Crossref

Grigoryan, V. G., J. K. Karapetyan (2008), Complex analysis of quantitative parameters of soil vibrations and assessment of their dependencies on earthquake magnitudes, Structural Mechanics and Analysis, No. 3, 59-63. (in Russian)

Ismail-Zadeh, A., S. Adamia, A. Chabukiani, et al. (2020), Geodynamics, seismicity and seismic hazards of the Caucasus, Earth Sci. Rev., 20\%, 103222, Crossref

Karapetyan, J. K. (2013), Comparative analysis of dynamic coefficient $\beta(T, n)$ curves obtained by different methods, Seism. Instr., 49, 307-314, Crossref

Karapetyan, J. K. (2017), Seismic safety and approaches for its implementation, Geoinformatics Research Papers, 5, 102 of 172, Crossref

Karapetyan, J. K. (2018a), Seismic safety instru- 
mental monitoring system, Book of Abstracts of the $36^{\text {th }}$ General Assembly of the European Seismological Commission, Univeristy of Malta, 27 Sep 2018, Valletta, Malta. (ESC2018-S2-926)

Karapetyan, J. K. (2018b), Seismic sensors for global seismic monitoring and earthquake research in Armenia, AGU100, American Geophysical Union, 10-14 Dec 2018, Washington D.C. (S13C-0459)

Karapetyan, J. K. (2018c), Study of seismicity and seismological investigations on the territory of Armenia, International Conference for the Decade Memory of the Wenchuan Earthquake with The $4^{\text {th }}$ International Conference on Continental Earthquakes (The $4^{\text {th }}$ ICCE) and The $12^{\text {th }}$ General Assembly of the Asian Seismological, the $4^{\text {th }}$ ICCE-0000000904, p. 908-916, ICCE, May 12-14, 2018, Chengdu, Sichuan, China.

Karapetyan, J. K., A. Gasparyan (2018), A new-type seismometer, 30 Years after the Spitak earthquake: experience and perspectives, AGU100, National Academy of Sciences of Armenia, 3-7 Dec 2018, Yerevan, Armenia. (6768)

Karapetyan, J. K., $\quad$ R. K. Karapetyan (2019), New Type of Sensor to Record Motion, AGU100, American Geophysical Union, 9-13 Dec 2019, San Francisco CA. (S41G-0604)

Karapetyan, J. K., R. S. Sargsyan, et al. (2020), Current state of study and actual problems of tectonics, seismology and seismotectonics of the territory of Armenia, Russ. J. Earth. Sci., 20, ES2005, Crossref

Mackey, K., D. Burk, K. Chalyy (2013), Preliminary work on new method for full station calibration of equipped skm and SM-3 seismometers,
The proceedings of scientific works of the conference is dedicated to the $70^{\text {th }}$ Anniversary of National Academy of sciences, National Academy of Sciences of Armenia, 3-5 May 2013, Yerevan, Armenia. (73-77)

Rykov, A. V. (1992), Seismometer, and oscillations of the Earth, Izvestiya AN SSSR. Fizika Zemli, No. 2, 76-80. (in Russian)

Rykov, A. V. (1992), The theory and practice of seismometry in Russia (to B.B. Galitzin's $140^{\text {th }}$ anniversary, Izvestiya AN SSSR. Fizika Zemli, 37, 24-37. (in Russian)

Sarkgsyan, V. K. (2010), Wide-band threecomponent seismometer with digital output, $I z v$. NAN. Ser. tekhn. nauk, 63, No. 3, 313-318. (in Russian)

Sarkgsyan, R. E. (2014), Modernization of the SM-3 seismometer, Seism. Instr., 50, 244-245, Crossref

Savarensky, E. F., $\quad$ D. P. Kirnos (2019), Modernization of the SM-3 seismometer, Elements of seismology and seismometry p. 384 p., Tehizdat, Moscow. (in Russian)

Sidorin, A. Ya. (2018), In memory of A.V. Rykov, Seism. Instr., 54, No. 4, 77-80.

Tokmakov, V. A. (1975), Seismometer SM-3, Seism. Instr., 8, 14-18. (In Russian)

Vasil'ev, I. M., Yu. P. Kozhevnikov, at al. (2016), Seismometers for monitoring systems, Science and Technological Developments, 95, No. 4, 5-10, Crossref

Corresponding author:

J. K. Karapetyan, Institute of Geophysics and Engineering Seismology after A. Nazarov NAS Republic of Armenia (jon_iges@mail.ru) 